\title{
Severe obstructive sleep apnea and long distance truck driving: A case report
}

\author{
Lisa N. Sharwood ${ }^{1 *}$, Jane Elkington ${ }^{1}$, Mark Stevenson ${ }^{2}$, Soufiane Boufous ${ }^{1}$, \\ Keith K. Wong ${ }^{3}$ \\ ${ }^{1}$ The George Institute for Global Health, Sydney, Australia; ${ }^{*}$ Corresponding Author: lsharwood@george.org.au \\ ${ }^{2}$ Accident Research Centre, Monash University, Melbourne, Australia \\ ${ }^{3}$ Respiratory and Sleep Medicine Unit, Royal Prince Alfred Hospital, Sydney, Australia
}

Received 18 January 2012; revised 28 February 2012; accepted 20 March 2012

\begin{abstract}
Introduction: Untreated sleep disorders can increase driver crash risk by up to 7 fold, and truck drivers have a variety of risk factors for sleep disorders. Measures currently used to identify drivers at risk depend predominantly on the ability of the driver to identify and report themselves as sleepy. Methods: This case report presents a $\mathbf{5 4}$ year old long distance truck driver who participated in a case-control study, underwent at home breathing monitoring and was followed up with an in-depth interview. Results: Self-reported measures did not identify this driver as at risk of sleepiness or sleep apnea; yet he was subsequently diagnosed with severe sleep apnea using an at home monitor and polysomnography. Conclusions: Self-assessment of risk factors is insufficient as a screen for sleep apnea. General practitioners are in an ideal position to identify potential sleep apnea sufferers and can initiate the enquiry process that leads to diagnostic testing.
\end{abstract}

Keywords: Sleepiness; Obstructive Sleep Apnea; Truck Driver; Licensing; Risk

\section{INTRODUCTION}

Untreated sleep disorders such as obstructive sleep apnea (OSA) can increase the crash risk of a car driver by up to 7 fold [1]. National regulatory amendments have specifically focused on the provision of adequate sleep and rest time for the long distance truck driver, while current licensing assessment standards attempt to identify drivers at risk of daytime sleepiness [2]. However, these tools predominantly depend on the ability of the driver to identify themselves as sleepy, and report this accurately.
Sleepiness is difficult to quantify objectively and therefore self-reported sleepiness levels may vary markedly between subjects; further, the sleep disordered breathing typically seen in OSA can often be insidious. Sufferers of OSA generally experience repeated bouts of upper airway obstruction during sleep; consequently hypoxia and multiple sleep disruptions throughout the night. It is well documented that sufferers can be quite unaware of nocturnal symptoms, such as snoring, apneas or gasping for breath during their sleep [3], particularly where there are other plausible reasons for perceived fatigue, such as shift work, long hours or use of stimulants to counter fatigue. OSA sufferers may also poorly identify their own daytime sleepiness. It is often the bed partner of an OSA sufferer who recognizes symptoms first, and encourages general practitioner (GP) consultation [4]. Truck drivers conducting long distance trips and spending more nights sleeping alone in their vehicle as opposed to their bed at home, therefore, may not be identified by a bed partner. Long distance truck drivers in Australia are predominantly male and overweight [5]; these factors, compounded by increasing age and the mostly sedentary nature of their work, put them at increased risk of OSA.

General practitioners are ideally placed to assess the risks for sleep disorder in truck drivers; however, they may encounter a number of problems. Firstly, as discussed, the sleep disturbed patient may not be aware of their symptoms and as such fail to report key identifiers [3]. It is also recognized that medical training contains very little content or preparation for understanding and accurately diagnosing disorders of sleep. Primary care physicians have been shown to largely under-diagnose sleep apnea and other sleep disorders and therefore fail to make the necessary referrals [6,7]. Previous research has identified over $80 \%$ of men with obstructive sleep apnea syndrome to have been undiagnosed [8]. This might be even higher among heavy vehicle drivers who have been found to have a higher prevalence of sleep apnea than the general population $[9,10]$. 
Current licensing of truck drivers in Australia follows the "Assessing Fitness to Drive" guidelines endorsed by all Australian driver licensing authorities [2], and includes a patient questionnaire and clinical examination before the findings are sent to the relevant licensing authority for each truck driver. The assessment includes the self-reported Epworth Sleepiness Scale (ESS) [11], designed to identify subjects at risk of daytime drowsiness; however, positive scores on this scale do not correlate well with diagnoses of OSA. For the truck driver, a heavy vehicle license is critical to employment and therefore their livelihood. Clearly this may present a conflict of interest to accurately report symptoms of sleepiness. Whilst nationally endorsed, the frequency with which this medical assessment must be completed for ongoing truck licensure varies significantly between states, lacking consistency in regular evaluation of risk.

We present this case report as clinical example of a 54 year old truck driver (whom we will call "John") with several risk factors for OSA, who, despite a 35 year career as a long distance truck driver had never presented himself for assessment nor been identified with a sleep disorder.

\section{METHODS}

The methods for the case-control study from which this case report driver came, have been previously described [12]. As with all study participants recruited as "controls" for the population based study, "John" was interviewed at a rural heavy vehicle refuelling and rest station. The interview of approximately 40 minutes duration, outlined demographics, anthropometry, driving and crash history, schedule and payment information, truck load and configuration, sleep quantity and quality, health and medical information, substance use, the Epworth Sleepiness Scale [11] and the Multivariable Apnea Prediction Index [13].

The Epworth Sleepiness Scale (ESS) was used to determine subjective sleepiness; the total score derived from responses on a Likert scale to 8 questions that ask the persons likelihood of "dozing off" in given situations. A score greater than 10 is considered to indicate daytime drowsiness. The Multivariable Apnea Prediction Index (MAPI) was calculated from questionnaire responses and demographic data; [13] the index score obtained represents the probability of having OSA, with a score greater than 0.5 considered at risk.

All study participants were subsequently sent a Flow Wizard $^{\mathrm{TM}}$ to wear during one night of sleep-a portable single channel nasal flow monitoring device used for the diagnosis of obstructive sleep apnea, well validated against the gold standard of polysomnography [14-17]. The Flow Wizard $^{\mathrm{TM}}$ report numbers all apneas and hypopnoeas dur- ing the episode of sleep recorded, summarised by the mean apnea hypopnea index (AHI). An AHI of 18 or more is interpreted to indicate risk of OSA and if 30 or more is classified as severe OSA. Results of the flow monitor test were sent to all participants, along with a letter explaining their meaning and a recommendation to seek further medical advice if a diagnosis of either moderate or severe sleep apnea was made. All drivers with these positive results were telephoned within the subsequent months to determine their receipt of these results and any actions taken. This case report driver presented with the most severe AHI in the whole study of 1047 drivers. John volunteered to "share his story" from an interest in describing his experiences for other drivers, researchers and the medical community at large.

Written informed consent was obtained from this participant. The questionnaire was approved by the Human Research and Ethics Committees at the University of Sydney.

\section{RESULTS}

Table 1 presents general demographic information from the truck stop interview, with a focus on health risks and behaviours.

The subject also reported his average sleep latency over the preceding month, as well as quantity and quality of sleep and perceived sufficiency of sleep during this time. The flow monitor was sent to "John" within 3 weeks of his truck stop interview for him to undertake during one night of sleep at home; he did so and returned this within 21 days. Table 2 describes specific risk factors for sleepiness and sleep disorder, as well as the re-

Table 1. Demographics and health behaviours.

\begin{tabular}{ll}
\hline Age, years & 54 \\
Driving experience, years & 35 \\
BMI $^{*}$ & 30 (obese) \\
Medical History & nil known \\
Smoking & none \\
Alcohol (standard drinks) & \\
$\quad$ - weekday & none \\
$\quad$ - days off & approx 9 \\
Illicit Drug Use & none \\
Caffeinated beverages (per day) & 4 cups \\
Energy Drinks (per day) & 1 - 2 \\
Exercise & no regular \\
Crash History 5 yrs & 0 \\
\hline
\end{tabular}

*BMI: Body Mass Index kg/m². 
Table 2. Summary of sleep related and sleep apnea results.

\begin{tabular}{ll}
\hline AHI, events/hour & 102 breathing disordered events/hour \\
\hline MAP Index & 0.83 (positive) \\
ESS & 9 \\
Snoring & Always \\
Snorting/gasping & Always \\
Choking/breath stops & Always \\
Average hrs sleep & \\
When working & 8.5 \\
Days off & 9.5 \\
Sleep Quality & "good” \\
Sleep Latency (mins) & 15 \\
Sufficient Sleep & yes \\
Drowsy driving? & $1-2 x /$ month \\
\hline
\end{tabular}

AHI = Apnea Hypopnoea Index from Flow Wizard sleep apnea monitor, ESS $=$ Epworth Sleepiness Scale, MAP $=$ Multivariable Apnea Prediction Index.

sults from the flow monitor test, and calculated indices from interview information.

Upon receipt of the letter of results "John" described an initial period of shock, not shared by his partner, a nurse, who had reportedly been "telling (him) for years" that he had a sleep disorder and needed to pursue treatment. He made an appointment to see his GP within the week, and was prioritized into a sleep laboratory within 48 hours from this visit. He underwent polysomnography which confirmed the flow monitor results; he was reported to have had "about 110 breathing pauses an hour during the sleep study", and oxygen desaturations down to $35 \%$. He was prescribed continuous positive airway pressure (CPAP) delivered from a portable machine via nasal mask every night.

When questioned in the second interview about the responses in the first to the Epworth Sleepiness Scale, and other questions regarding his level of daytime sleepiness, he replied "I didn't know how bad I felt until I realized how good I feel now". In retrospect he was able to articulate a significant effect on his working and home life over the past few years due to constant tiredness. He described the previous few months prior to OSA diagnosis as "exhausting"; he was waking each morning at 5 am with a "pounding migraine", taking analgesics and going back to bed. He described starting work at 6 am and "needing a nap by 9 am". However, his work schedule did not necessarily permit this; therefore he would continue driving. He described having a ten hour sleep at night, yet awaking feeling as though he had barely slept. He expressed the frustration felt by his partner and chil- dren who were unable to spend any quality time with him, as he "fell asleep in the chair" as soon as he returned from work.

When asked to describe how he felt now using CPAP every night and sleeping with a mask, he said "The benefits of how I feel now far outweigh the disadvantages of using a machine every night, and I would rather live with this than go back to the way I was before". He portrayed a complete change in his family life, now travelling overseas, going on 4WD trips camping with his family, and feeling "like a new man". He reported very good compliance with CPAP which had been verified by his sleep specialist, and described "much greater" alertness behind the wheel of his heavy vehicle, with no difficulty taking his CPAP machine in the vehicle if he needed to do an overnight trip. "It's just like remembering your toothbrush and change of underwear." Both his work and home life had significantly improved as a result of treatment of this disorder.

\section{DISCUSSION}

This case report describes significant differences in one man's reported perception of his sleep health and sleepiness between pre and post clinical diagnosis with obstructive sleep apnea. The main message for the GP is to be aware of the limitations of self report for this disorder, and therefore probe widely to identify key indicators for sleep apnea, developing a comprehensive risk profile of the driver.

The results presented above obtained in the initial interview, highlight some indicators of risk for OSA in this man; namely his BMI, age and gender, and symptoms of respiratory disturbance such as regular snoring and choking or gasping for breath during sleep. Despite having severe OSA, and in retrospect, acknowledging the presence of significant associated functional impairment, his diagnosis and subsequent treatment was only triggered by directed questioning and testing for OSA, performed within the context of a research study. This case highlights the importance of being alert to the features of the disease, and where appropriate, considering the need for further testing.

In the research study, the only test that identified this man to be at risk of OSA was the MAP Index, consistent with the fact that he was later diagnosed with OSA, however, other symptom-derived questionnaires did not. This is designed to indicate presence of OSA, and, in common with many other algorithms [18], this has been validated against the "gold standard" of polysomnography in a sleep clinic population of referred patients [19], however it is yet to be validated in a general population. The lack of sensitivity of other questionnaire items to his OSA risk might be explained by his inability to recog- 
nize his sleepiness symptoms, perhaps because it was of insidious onset, or alternatively because fears related to potential loss of livelihood in a truck driver population may result in under-reporting of symptoms. This has been seen in previous research, where 1443 truck drivers were screened using a combination of data to identify OSA; 190 (13\%) were identified as having a high risk of OSA and needing PSG, however, none of the 1443 drivers completing the medical form required for licensure reported they had a sleep disorder or, pauses in breathing while asleep, daytime sleepiness or loud snoring [20]. "John" admitted in his $2^{\text {nd }}$ interview that he "didn't know how bad he felt, until he knew how good (he felt)," on OSA treatment.

Commercial motor vehicle drivers with severe OSA suffer notably from sleepiness and impaired task performance [21], thereby increasing their risk of crashing. However, treatment of severe OSA with CPAP has shown improved alertness and reduced crash risk among general car drivers [22,23]. For these reasons, added to the cost of crashes involving heavy vehicles, it is imperative for general practitioners consulting with truck drivers to identify those patients at risk, and recommend further assessment. Gurubhagavatula et al. [24] determined that screening using BMI, age and gender alone or with oximetry, is a feasible strategy to identify truck drivers likely to have OSA syndrome (as defined by positive MAP Index and positive ESS score). However, as described in this case report, drivers such as "John", with a self-reported negative ESS, will go undetected and therefore remain at risk. Further validation of screening tools or algorithms such as the MAP Index is necessary to aid the accurate identification of truck drivers with OSA.

Previous research in men's health has shown that, compared with women, men are less likely to consult their GP for health concerns [25], will utilize available health screening checks to a lesser degree [26] and are more likely to report fewer symptoms and also delay seeking help for symptoms until later in episodes of illness [27]. To accommodate this, the GP would find the testimony of a wife/bed partner helpful, as well as information regarding work absences due to illness or fatigue. It is also important to cover a broad range of symptoms, rather than concentrating on one or two symptoms or the ESS alone. Aside from the physical indicators that imply risk, such as overweight, male gender and middle age, a GP could look to clues such as:

1) Bed partner expressing concerns about breathing disturbances during sleep.

2) Reports of regular or recent drowsy driving.

3) Reports of diminished participation in evening activity with family and friends.

4) Reports of not feeling refreshed upon waking.

The general practitioner assessing a truck driver for health risks and new or continued licensure must be aware of the full range of OSA symptoms and risks, as well as the limitations of the existing assessment tools.

\section{ACKNOWLEDGEMENTS}

This work was supported by an Australian Postgraduate Awards Industry grant (Australian Research Council) [to LNS], and an NHMRC Fellowship [to MS]. We acknowledge full study funding support from the Australian Research Council, the Australian Government Department of Infrastructure, Transport, Regional Development and Local Government, DiagnoseIT, the National Transport Commission, Queensland Transport, the Roads and Traffic Authority of New South Wales and Main Roads in Western Australia.

\section{REFERENCES}

[1] Young, T., Blustein, J. and Finn, L. (1997) Sleep-disordered breathing and motor vehicle accidents in a populationbased sample of employed adults. Sleep, 20, 608-613.

[2] Austroads (2006) Assessing fitness to drive for comercial and private vehicle drivers. Austroads and NTC.

[3] Bailes, S., Baltzan, M., Rizzo, D., Fichten, C., Grad, R., Wolkove, N., et al. (2009) Sleep disorder symptoms are common and unspoken in Canadian general practice. Family Practice, 26, 294-300. doi:10.1093/fampra/cmp031

[4] Punjabi, N. (2008) The Epidemiology of adult obstructive sleep apnea. Proceedings American Thoracic Society, 5, 136-143. doi:10.1513/pats.200709-155MG

[5] Howard, M., Desai, A., Grunstein, R., Hukins, C., Armstrong, J., Joffe, D., et al. (2004) Sleepiness, sleep-disordered breathing, and accident risk factors in comer- cial vehicle drivers. American Journal of Respiratory \& Critical Care Medicine, 170, 1014-1021. doi:10.1164/rccm.200312-1782OC

[6] Chung, S., Jairam, S., Hussain, M. and Shapiro, C. (2001) Knowledge of sleep apnea in a sample grouping of primary care physicians. Sleep and Breathing, 5, 115-121. doi:10.1055/s-2001-17429

[7] Papp, K., Penrod, C. and Strohl, K. (2002) Knowledge and attitudes of primary care physicians toward sleep and sleep disorders. Sleep and Breathing, 6, 103-109. doi:10.1055/s-2002-34317

[8] Young, T., Evans, L., Finn, L. and Palta, M. (1997) Estimation of the clinically diagnosed proportion of sleep apnea syndrome in middle-aged men and women. Sleep, 20, 705-706.

[9] Bearpark, H., Elliott, L., Grunstein, R., Schneider, H., Althaus, W. and Sullivan, C. (1995) Snoring and sleep apnea: A population study in Australian men. Respiratory and Critical Care Medicine, 151, 1459-65.

[10] Pack, A., Dinges, D. and Maislin, G. (2002) A study of prevalence of sleep apnea among commercial truck drivers. Federal Motor Carrier Safety Administration, Washington DC.

[11] Johns, M. (1991) A new method for measuring daytime sleepiness: The Epworth sleepiness scale. Sleep, 14, 540- 
545.

[12] Stevenson, M, Sharwood, L.N., Wong, K., Elkington, J., Meuleners, L., Ivers, R.Q., et al. (2010) The Heavy Vehicle Study: A case-control study investigating risk factors for crash in long distance heavy vehicle drivers in Australia. BMC Public Health, 10, 162. doi:10.1186/1471-2458-10-162

[13] Maislin, G., Pack, A.I., Kribbs, N., Smith, P., Schwartz, A., Kline, L., et al. (1995) A Survey Screen for Prediction of Apnea. Sleep, 18, 158-166.

[14] Rofail, L., Wong, K., Unger, G., Marks, G. and Grunstein, R. (2010) The utility of single-channel nasal airflow pressure transducer in the diagnosis of OSA at home. Sleep, 33, 1097-1105.

[15] Rofail, L., Wong, K., Unger, G., Marks, G. and Grunstein, R. (2010) Comparison between a single-channel nasal airflow device and oximetry for the diagnosis of obstructtive sleep apnea. Sleep, 33, 1106-1114.

[16] Rofail, L., Wong, K., Unger, G., Marks, G. and Grunstein, R. (2010) The role of single-channel nasal airflow pressure transducer in the diagnosis of OSA in the sleep laboratory. Journal of Clinical Sleep Medicine, 6, 349-356.

[17] Wong, K., Jankelson, D., Reid, A., Jankelson, D., Unger, G, Dungan, G., et al. (2008) Diagnostic test evaluation of a nasal flow monitor for obstructive sleep apnea detection in sleep apnea research. Behavior Research Methods, 40, 360-366. doi:10.3758/BRM.40.1.360

[18] Moreno, C.R.C., Carvalho, F.A., Matuzaki, L.S., Prezotti, S., Bighetti, P., Louzada, F.M., et al. (2004) High risk for obstructive sleep apnea in truck drivers estimated by the Berlin Questionnaire: Prevalence and associated factors. Chronobiology International, 21, 871-879. doi:10.1081/CBI-200036880

[19] Gurubhagavatula, I., Maislin, G. and Pack, A. (2001) An algorithm to stratify sleep apnea risk in a sleep disorders clinic population. American Journal of Respiratory \& Criti- cal Care Medicine, 164, 1904-1909.

[20] Talmage, J., Hudson, T., Hegmann, K. and Thiese, M. (2008) Consensus Criteria for screening commercial drivers for obstructive sleep apnea: Evidence of efficacy. Journal of Occupational and Environmental Medicine, 50, 324-349. doi:10.1097/JOM.0b013e3181617ab8

[21] Pack, A., Maislin, G., George, C., Pack, F. and Dinges, D. (2001) Factors associated with daytime sleepiness and performance in a sample of commercial drivers. Sleep, 24, A427.

[22] George, C. (2001) Reduction in motor vehicle collisions following treatment of sleep apnea with nasal CPAP. Thorax, 56, 508-512. doi:10.1136/thorax.56.7.508

[23] Sullivan, C., Issa, F., Berthon-Jones, M. and Eves, L. (1982) Reversal of obstructive sleep apnea by continuous positive airways pressure applied through the nares. Lancet, $\mathbf{1}$, 862-865.

[24] Gurubhagavatula, I., Nkwuo, J.E., Maislin, G. and Pack, A.I. (2008) Estimated cost of crashes in commercial drivers supports screening and treatment of obstructive sleep apnea. Accident Analysis and Prevention, 40, 104-115. doi:10.1016/j.aap.2007.04.011

[25] Kapur, N., Hunt, I., Lunt, M., McBeth, J., Creed, F. and MacFarlane, G. (2004) Psychosocial and illness related predictors of consultation rates in primary care. Psychological Medicine, 34, 719-728. doi:10.1017/S0033291703001223

[26] Thorogood, M., Coulter, A., Jones, L., Yudkin, P., Muir, J. and Mant, D. (1993) Factors affecting response to an invitation to attend general health check. Journal of Epidemiology and Community Health, 47, 224-228. doi:10.1136/jech.47.3.224

[27] Gijspbers van Wijk, C., Huisman, H. and Kolk, A. (1999) Gender differences in physical symptoms and illness behaviour: A health diary study. Social Science and Medicine, 49, 1061-1074. 